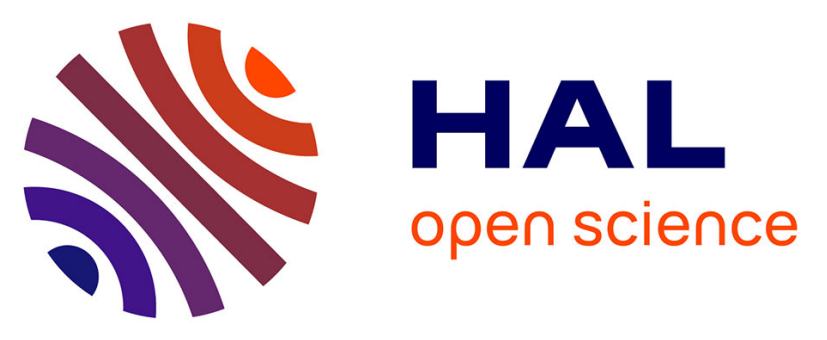

\title{
Compression of vectors for small interfering RNAs delivery: toward oral administration of siRNA lipoplexes in tablet form
}

Virginie Busignies, Danielle Campiol Arruda, Christine Charrueau, Marcela Coelho Silva Ribeiro, Anne-Marie Lachagès, Angelo Malachias, Stéphanie Finet, Asad Ur Rehman, Pascal Bigey, Pierre Tchoreloff, et al.

\section{To cite this version:}

Virginie Busignies, Danielle Campiol Arruda, Christine Charrueau, Marcela Coelho Silva Ribeiro, Anne-Marie Lachagès, et al.. Compression of vectors for small interfering RNAs delivery: toward oral administration of siRNA lipoplexes in tablet form. Molecular Pharmaceutics, 2020, 17 (4), pp.11591169. 10.1021/acs.molpharmaceut.9b01190 . hal-03407297

\section{HAL Id: hal-03407297 \\ https://cnrs.hal.science/hal-03407297}

Submitted on 28 Oct 2021

HAL is a multi-disciplinary open access archive for the deposit and dissemination of scientific research documents, whether they are published or not. The documents may come from teaching and research institutions in France or abroad, or from public or private research centers.
L'archive ouverte pluridisciplinaire HAL, est destinée au dépôt et à la diffusion de documents scientifiques de niveau recherche, publiés ou non, émanant des établissements d'enseignement et de recherche français ou étrangers, des laboratoires publics ou privés. 
Compression of vectors for small interfering RNAs delivery: toward oral administration of siRNA lipoplexes in tablet form

Virginie Busignies ${ }^{a}$, Danielle Campiol Arruda ${ }^{b, c}$, Christine Charrueau ${ }^{c}$, Marcela Coelho Silva Ribeiro $^{b, c}$, Anne-Marie Lachagès ${ }^{c}$, Angelo Malachias ${ }^{d}$, Stéphanie Finet ${ }^{e}$, Asad Ur Rehman $^{c}$, Pascal Bigey, ${ }^{c, f}$ Pierre Tchoreloff ${ }^{a}$, Virginie Escriou $^{c *}$

${ }^{a}$ Univ. Bordeaux, CNRS, Arts et Metiers Institute of Technology, Bordeaux INP, INRAE, I2M Bordeaux,F-33400 Talence, France

${ }^{\mathrm{b}}$ Faculdade de Farmácia, Universidade Federal de Minas Gerais, 31270-901 Belo Horizonte, MG, Brazil

c Université de Paris, UTCBS, CNRS, INSERM, F-75006 Paris, France

${ }^{\mathrm{d}}$ Departamento de Física, Universidade Federal de Minas Gerais, 31270-901 Belo Horizonte, MG, Brazil

${ }^{\text {e }}$ Sorbonne Université, IMPMC, CNRS, MNHN, F-75005 Paris, France

${ }^{f}$ PSL University, ChimieParisTech, F-75005 Paris, France

* corresponding author: Dr. Virginie ESCRIOU

UTCBS, CNRS UMR 8258, Faculté de Pharmacie, 4 avenue de l'Observatoire, 75270 Paris cedex 06, France, Tel: 33153739575 Fax: 33170649452

virginie.escriou@parisdescartes.fr 
Keywords: RNA interference; cationic lipid; nanoparticle; delivery system; structure; anionic polymer; compression; tablets

\begin{abstract}
:
Currently, most non-viral nucleic acid vectors are in the form of colloidal suspensions administered primarily parenterally. This type of formulation and the mode of administration impose strong constraints such as the size of the administered vectors or the production of sterile preparations. The tablet form provides access to easy oral administration, well accepted by patients, it is also an advance for the stability of the nucleic acids vectors, since it is a dry form.
\end{abstract}

Using an optimized lipid-based small interfering RNA delivery system, we studied the tabletability of a liquid suspension of these vector. We optimized the conditions of freeze-drying by choosing excipients and process, allowing for the conservation of both the gene silencing efficacy of the formulated siRNAs and the supramolecular structure of the lipid particulate system. Gene silencing efficacy was assayed on luciferase-expressing cells and the structure of the siRNA vector in freezedried and tablet forms was examined using SAXS Synchrotron radiation. The freeze-dried powders were then mixed with excipients necessary for the good progress of the compression by allowing for a regular supply of the matrix and the reduction of friction. The compression was carried out using a rotary press simulator that allow for complete monitoring of the compression conditions. After compression, formulated siRNAs retained more than $60 \%$ of their gene silencing efficacy. Within the tablets, a specific SAXS signal was detectable and the lamellar and cubic phases of the initial liquid suspension were restored after re-suspension of siRNA vectors by disintegration of the tablets. These results show that the bilayer lipid structures of the particles were preserved despite the mechanical constraints imposed by the compression. If such a result could be expected after the freeze-drying step, it was never shown, to our knowledge, that siRNA delivery systems could retain their efficacy and structure after mechanical stress such as compression. This opens promising perspectives to oral administration of siRNA as an alternative to parenteral administration. 


\section{Introduction}

The oral route as a means of drug delivery remains the most appealing route due to high patient compliance and ease of administration. Consequently, the oral dosage forms represent $80 \%$ of the pharmaceutical forms on the market. ${ }^{1}$ This administration route allows for local therapeutic effects to treat diseases located in the digestive tract, as well as systemic passage. However, despite these advantages, the oral route remains relatively little considered for nucleic acids delivery due to the various obstacles to overcome before reaching their intracellular site of action, including i) physiological barriers, i.e. $\mathrm{pH}$ variations along the gastrointestinal tract, presence of degradative enzymes and mucus, and ii) cellular barriers of the intestinal mucosa composed of an epithelial layer, lamina propria and muscularis mucosa. ${ }^{2}$

The small interfering RNAs or siRNAs are small double-stranded RNAs that can bind specifically to a messenger RNA and thus prevent the expression of a gene by cleaving its corresponding mRNA. ${ }^{3}$ One of the potential advantages of sequence-based gene suppression technologies is the ability to design precisely targeted therapeutics for almost any gene, regardless of the function of the gene product, whether that function is clearly defined, and in the absence of any protein structure information. Since siRNAs are unable to reach on their own their site of action, i.e. the cytoplasm of target cell, they are most often vectorized within nanoparticles, of lipid or polymeric type, in the form of liquid suspension. ${ }^{4-5}$ The first therapy based on RNA interference (RNAi) gene silencing, termed Onpattro ${ }^{\circledR}$, has been approved by the US Food and Drug Administration in $2018 .^{3}$ This lipid complex suspension, for intravenous use, contains a transthyretin-directed siRNA and is indicated for the treatment of the polyneuropathy of hereditary transthyretin-mediated amyloidosis in adults. ${ }^{6}$ Likewise, the vast majority of siRNA-based drug candidates are administered locally or systemically. ${ }^{7}$ However, some pre-clinical studies of oral delivery of siRNA have been reported (reviewed in ${ }^{2,8}$ ). In these studies, siRNA was administered by gavage to mice or rats, in the form of liquid suspension of nanoparticles, either as such or incorporated into polymeric microspheres. Usually, these nanoparticle suspensions are freshly prepared for each experiment, for instance by auto assembly of the components upon mixing of aqueous solutions or suspensions. ${ }^{9}$ Although this process results in robust particle formation over shorter time periods, it is not applicable in a clinical setting or if long term storage is required. In terms of stability, preservation of sterility or long-term storage, dry forms are much more attractive. ${ }^{10-11}$ Freeze-drying has been widely used as a standard method to present various drugs into a dry form (in particular biopharmaceutics), as it prevents hydrolysis and physical degradation during extended storage. ${ }^{12}$ Yet, the obtained freeze-dried powder is not suitable to be delivered as such via oral route and requires an additional process to produce administrable solid dosage forms like tablets. It has not yet been established whether siRNA vectors are able to 
withstand the stresses inherent in the preparation of pharmaceutical tablets. In fact, it is well known that the particular structure adopted by their components is closely associated with their efficacy, especially when lipids are used and form bilayers. ${ }^{13}$ Keeping these structures, essential to their activity, after tableting process is still to be demonstrated.

In this study, we have used a siRNA delivery vector, based on cationic lipid and anionic adjuvant, that we previously designed and for which gene silencing efficacy was shown in different mice models of disease. ${ }^{14-16}$ An aqueous suspension of this vector was submitted to a freeze-drying process in the presence of various lyophilization excipients. After that, the solid samples resulting from freezedrying process were compacted to obtain tablets. The gene silencing activity of these siRNA delivery systems was assayed along with the impact of the processes on the supramolecular structure of the vectors.

\section{Experimental Section}

\section{Materials}

siRNA (unmodified) specific to luciferase (sense strand, 5' CUU ACG CUG AGU ACU UCG AdTdT 3') or non-silencing siRNA used as negative control (sense strand, 5' UUC UCC GAA CGU GUC ACG UdTdT 3') were obtained from Eurogentec (Seraing, Belgium). Sodium alginate (reference 180947), sucrose, glucose and dry methanol (methanol 99.9\%, Extra dry, AcroSeal ${ }^{\circledR}$ ) were purchased from SigmaAldrich (St. Quentin Fallavier, France). DOPE (1,2-dioleoyl-sn-glycero-3-phosphoethanolamine) was obtained from Avanti Polar Lipids (Coger SAS, Paris, France). Mannitol (Pearlitol ${ }^{\circledR} 400$ DC) was obtained from Roquette (Lestrem, France), trehalose (Treha $\left.{ }^{\circledR} 16400\right)$ from Cargill (Paris La Défense, France), lactose (FlowLac ${ }^{\circledR} 90$ ) from Meggle (Wasserburg, Germany) and magnesium stearate from Cooper (Melun, France).

\section{Preparation of siRNA lipoplexes}

Cationic liposomes were prepared from cationic lipid DMAPAP (2-\{3-[Bis-(3-amino-propyl)-amino]propylamino\}-N-ditetradecylcarbamoyl methyl-acetamide) ${ }^{17}$ and zwitterionic lipid DOPE (1/1, M/M) at $20 \mathrm{mM}$ in $\mathrm{H}_{2} \mathrm{O}$ as previously described. ${ }^{18}$ Lipoplexes (+/- $\mathrm{R} 8$ ) were prepared by mixing an equal volume of a solution, containing siRNA (luciferase or control) and sodium alginate (ratio $1 / 1, w / w$ ) diluted in $150 \mathrm{mM} \mathrm{NaCl}$, and a suspension of cationic liposome suspension also in $150 \mathrm{mM} \mathrm{NaCl}$, and rapidly mixed by vortexing. Lipoplexes were allowed to form at least for $30 \mathrm{~min}$ at room temperature before use. The +/- charge ratio (+/- R) was calculated using the molar ratio of positive charges ( 3 positive charges per molecule of DMAPAP) and the molar ratio of negative charges (3.03 and 5.05 nmoles of negative charges/mg of siRNA and sodium alginate, respectively). In some assays, as 
indicated, saline $(150 \mathrm{mM} \mathrm{NaCl})$ was replaced by MilliQ water or glucose $(5 \% \mathrm{w} / \mathrm{v})$ or sucrose $(5 \%$ $w / v)$.

\section{Freeze-drying of siRNA lipoplexes}

Freeze-drying excipient solutions were prepared in water with the following concentrations: $3.5 \%$ $\mathrm{w} / \mathrm{v}$ of trehalose, or $5 \% \mathrm{w} / \mathrm{v}$ of trehalose, or $2.5 \% \mathrm{w} / \mathrm{v}$ of trehalose with $1 \% \mathrm{w} / \mathrm{v}$ of mannitol or $4 \%$ $\mathrm{w} / \mathrm{v}$ trehalose with $1 \% \mathrm{w} / \mathrm{v}$ of mannitol. $3.6 \mathrm{ml}$ of excipient solution were added to lipoplexes suspension $\left(400 \mu \mathrm{l}, 1.9 \mu \mathrm{M}\right.$ siRNA). The resulting suspension set in a $50 \mathrm{ml}$ tube (Falcon ${ }^{\circledR}$ centrifuge tube, Corning ${ }^{\circledR}$, New York, USA) was frozen in liquid nitrogen for 10 min and transferred on the rubber valves for connection to the drying chamber of a laboratory scale freeze-dryer (Christ-Alpha 1-4, Christ, Osterode am Harz, Germany) as shown on Figure 1C. Different lyophilisation cycles were performed based on the drying duration, i.e. 20, 24 or $30 \mathrm{~h}$ (duration corresponding to the primary and secondary drying). During runs, process parameters were kept constant, i.e. the ice condenser chamber was set at $-60^{\circ} \mathrm{C}$ and the chamber pressure was set at $0.2 \mathrm{mbar}$. Heat needed for sublimation was supplied from the atmosphere (the runs were performed at room temperature). Sample temperature was recorded during freeze-drying runs with the Tempris wireless temperature system (IQ Mobil Solutions GmbH, Wolfratshausen, Germany). SEM images of freeze dried powders were taken on a tabletop scanning electron microscope TM3000 (Hitachi, Japan).

\section{Tableting of freeze-dried products}

$160 \mathrm{mg}$ mixtures were produced with freeze-dried solids $(76.5 \% \mathrm{w} / \mathrm{w})$, lactose $(23 \% \mathrm{w} / \mathrm{w})$ and magnesium stearate $(0.5 \% \mathrm{w} / \mathrm{w})$. Then, the mixtures were compacted with a StylOne Evolution compression simulator (Medelpharm, Beynost, France) that was tooled with bevel-edged EuroB punches (diameter of $6 \mathrm{~mm}$ ). Different compaction pressures were applied (in the range of 50 to 250 $\mathrm{MPa}$ ) using the force driven mode of Analis software. Additional tablets were produced to perform characterizations such as apparent densities (in-die and out-of-die), elastic recovery and cohesion. To help the determination of geometrical parameters of tablets (thickness and diameter), Euro B round flat-faced punches with a diameter of $8 \mathrm{~mm}$ were used. SEM analysis of tablets (surface or inside) was performed on a tabletop scanning electron microscope TM3000 (Hitachi, Japan). The elastic recovery (\% ERT) was calculated as reported ${ }^{19}$ using the minimal volume under compaction $\left(\mathrm{V}_{\text {min }}\right)$ and the final volume of each tablet $\left(V_{f}\right)$. The tablets were measured directly after ejection, giving the final volume, $V_{f} . \% E R T$ is expressed by the following equation:

$$
\% E R T=\frac{V_{f}-V_{\min }}{V_{\min }} \times 100
$$




\section{Small-angle X-ray scattering (SAXS)}

SAXS measurements were carried out at the SWING beamline of SOLEIL (Gif-sur-Yvette, France), using a fixed energy of $12.0 \mathrm{keV}$. A PCCD170170 (AVIEX) 2D detector was placed at a $1.5 \mathrm{~m}$ distance from the sample, covering a momentum scattering vector $(Q)$ range that spans from 0.0075 until 0.8 $\AA^{-1}$. In this setup a resolution of $0.00067 \AA^{-1}$ is achieved. All measured scattering patterns are angularly isotropic in this work. Hence, our datasets are shown after an angular integration of the detector area (commonly referred as "cake"), averaged and background subtracted using FOXTROT program (V3.4.1, Xenocs). Suspensions or powders (freeze-dried samples or crushed tablets) were inserted manually into a capillary. Resuspension of samples occurred several hours prior to the SAXS analysis. Lipoplexes suspensions were prepared in $100 \mu \mathrm{l} \mathrm{NaCl} 150 \mathrm{mM}$ with a final concentration of siRNA of $20 \mathrm{mM}$. Ten to 60 frames were recorded with an acquisition time from 10 to $300 \mathrm{msec}$ depending upon the samples (powder or suspension).

\section{Gene silencing on cultured cells}

B16-Luc were obtained and transfected as described. ${ }^{20-21}$ Freeze-dried powders and tablets were diluted in $4 \mathrm{ml}$ milliQ water. Lipoplexes with luciferase siRNA or control siRNA were freshly prepared as positive and negative controls, respectively. Suspensions were diluted in complete culture cell medium (siRNA concentration $37.5 \mathrm{nM}$ ) and added to cells for $24 \mathrm{~h}$ in 24-well plates. Transfection medium was replaced by fresh medium for another $24 \mathrm{~h}$, then the transfected cells were washed twice with PBS and lysed, and luciferase and total protein were assayed as in ${ }^{22}$. The results, calculated in cps (count per second), were normalized to the total protein concentration of each sample and the gene silencing efficacy was expressed as the luciferase activity inhibition percentage relative to the luciferase activity of non-transfected control cells.

\section{Statistical analysis}

All results were analyzed with the unpaired non-parametric Mann-Whitney test using two-tailed Pvalues. Results with $p<0.05$ were considered statistically significant.

\section{Results}

\section{Freeze-drying of siRNA lipoplexes}

The purpose of the compression process is to obtain tablets from a powder by volume reduction and cohesion acquisition by particle deformation. The first step of this study was therefore to obtain a powder from the liquid suspension of siRNA nanoparticles. We used our optimal siRNA delivery system, termed siRNA lipoplexes and composed of the cationic lipid DMAPAP, the zwitterionic lipid DOPE, the anionic polymer sodium alginate and siRNA. This innovative patented vector ${ }^{23}$ is obtained 
by self-assembly of the components upon mixing of the cationic liposome suspension with the mixture of siRNA and anionic polymer in solution. Once prepared, the obtained lipoplexes were mixed with a solution of well-studied freeze-drying excipients ${ }^{24-25}$ composed of trehalose $(2.5 \% \mathrm{w} / \mathrm{v})$ and mannitol $(1 \% \mathrm{w} / \mathrm{v})$. Then, before being freeze-dried, the samples were submitted to a fast prefreezing step (10 min in liquid nitrogen) (Figure 1) in order to promote an amorphous solid or, at least, the production of very small ice crystals and then avoid the disruption of lipoplexes. The obtained freeze-dried solid exhibited a porous, friable, water-greedy texture allowing its almost immediate and complete re-suspension upon addition of water. The cake obtained was slightly crushed in order to produce a powder that could be used for further experiments.

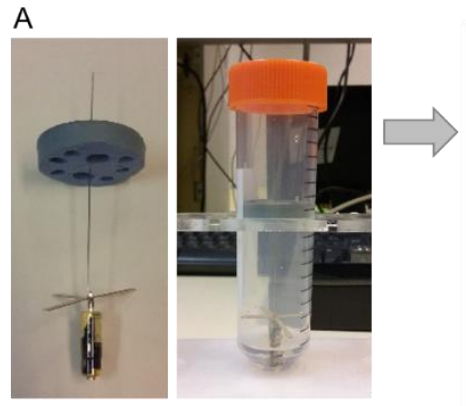

$\mathrm{E}$

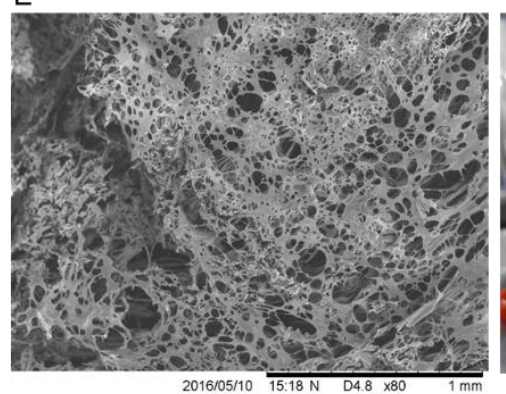

B
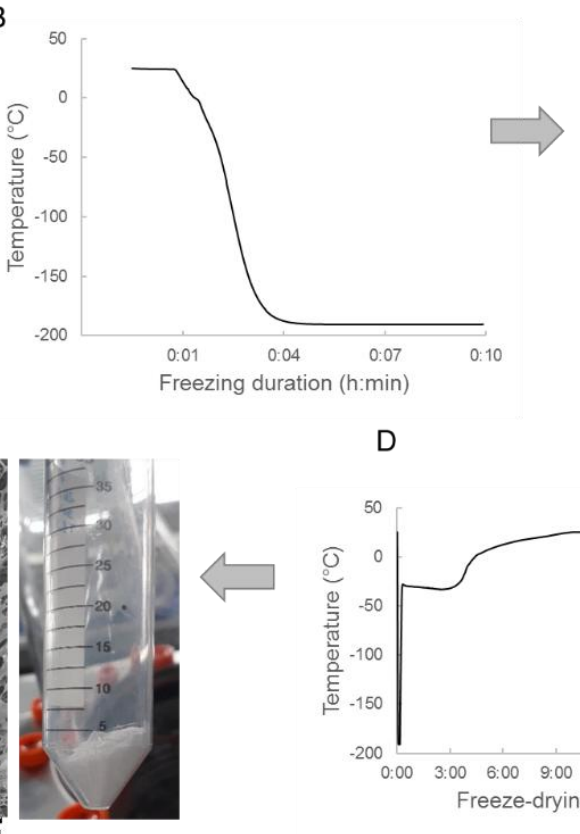

D
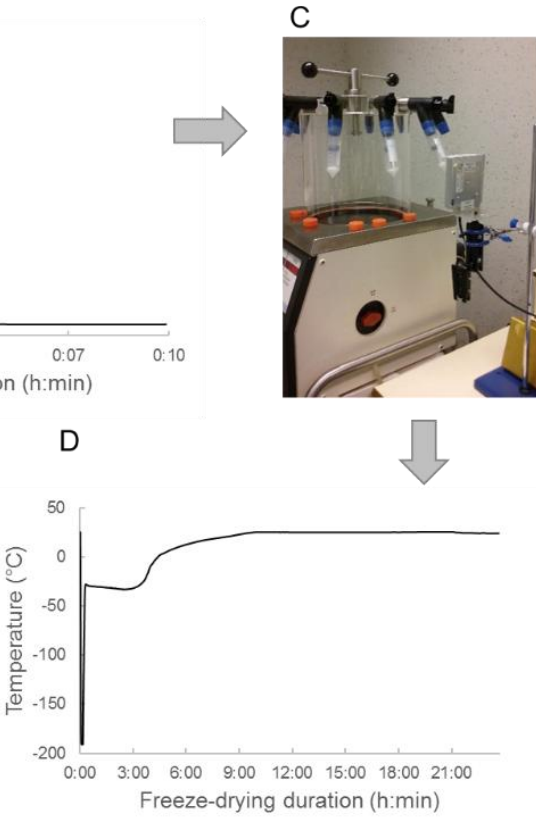

Figure 1. Freeze-drying process for suspensions of lipoplexes in trehalose / mannitol 2.5/1 \% w/v. (A) Lipoplexes suspension sample (right) with Tempris probe (left). (B) Temperature over time profile during freezing step in liquid nitrogen. (C) Samples in process during lyophilization cycle (monitoring of internal temperature over the time period of the cycle). (D) Temperature over time profile during freezing and drying phases. (E) Final freeze-dried sample (left, SEM images; right, macroscopic aspect of cake).

The gene silencing efficacy of re-suspended lipoplexes was assayed on cultured cells. Preserving lipoplexes efficacy was our first selection criterion, since it implied that the vector structure was maintained. As shown on Figure 2A, the efficacy of lipoplexes re-suspended after freeze-drying was identical to that of fresh lipoplexes. This efficacy is specific since it depends on the sequence of siRNA (no gene silencing with lipoplexes prepared with control siRNA). It was not affected by the presence of lyophilization excipients since the incubation of fresh lipoplexes in the trehalose / mannitol mixture did not modify their efficacy (Figure 2A, excipients). The effect of the duration of freezedrying on the efficacy of the re-suspended lipoplexes was also evaluated and it was found that the 
efficacy was the same for a duration of 20, 24 or 30 hours of freeze-drying (Figure 2B). Then, a duration of $30 \mathrm{~h}$ for freeze-drying was chosen for the following experiments. We also assayed other solutions to prepared lipoplexes, i.e water, glucose or sucrose $(5 \% \mathrm{w} / \mathrm{v})$. Lipoplexes were then prepared in these solutions, diluted in trehalose / mannitol solution and freeze-dried in the same conditions as above (cycle duration of $30 \mathrm{~h}$ ), before being re-suspended by adding water and assayed for efficacy. As shown in Figure $2 \mathrm{C}, \mathrm{NaCl}$ is necessary to obtain lipoplexes which retain complete gene silencing efficacy after freeze-drying and re-suspension. This observation has already been made by several teams working on lipoplexes ${ }^{26-28}$ and several hypotheses have been proposed to explain the role of salt in obtaining effective lipoplexes, such as an increase in stability, size, internalization and / or association by cells. However, no consensus seems to emerge and the effect seems to depend on the cationic lipid used. We then kept $\mathrm{NaCl}$ in the lipoplexes preparation solution.

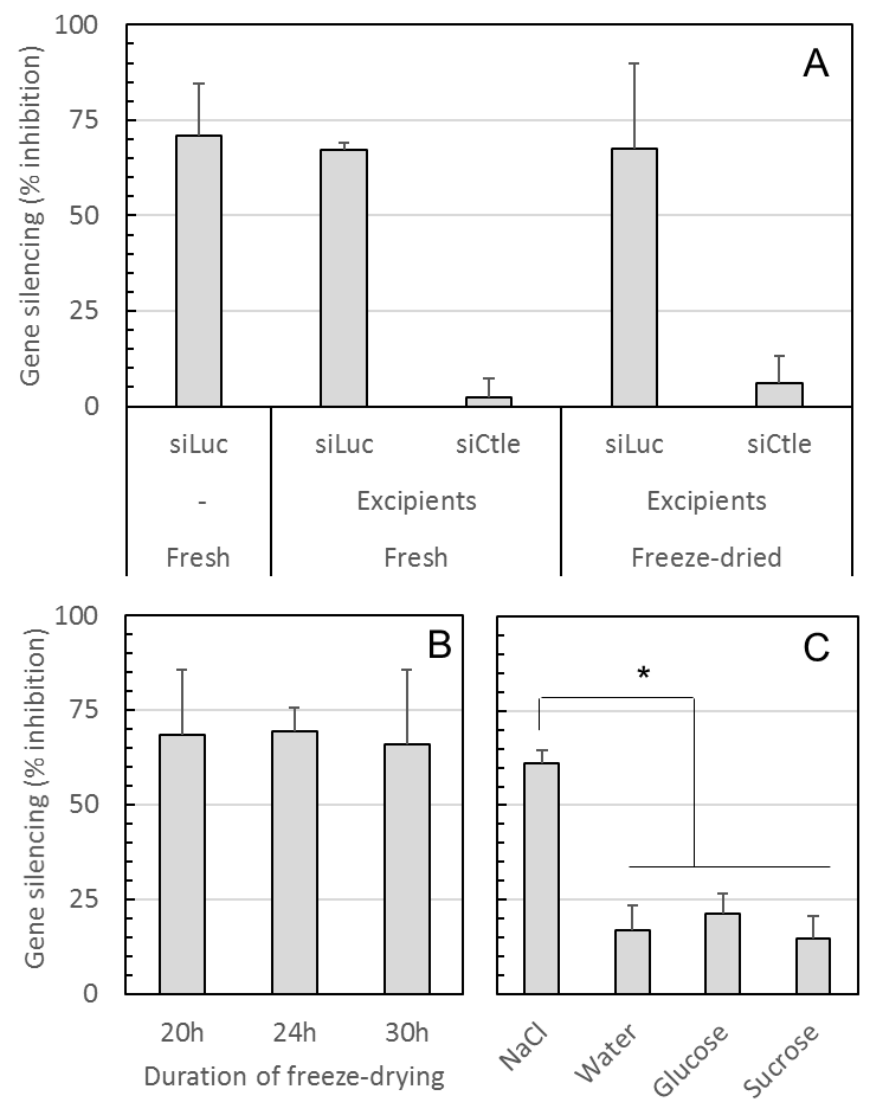

Figure 2. Gene silencing efficacy of re-suspended lipoplexes after freeze-drying on B16 cells expressing luciferase. Lipoplexes are either freshly prepared (Fresh), or diluted in freeze-drying excipients (trehalose / mannitol $2.5 \%$ / $1 \% \mathrm{w} / \mathrm{v}$ ) and tested as such without freeze-drying (Excipients - Fresh) or after freeze-drying for $30 \mathrm{~h}$ and re-suspension (Excipients Freeze-dried) ( $\mathrm{n}=5$ to 7). (B) Lipoplexes were prepared with siLuc and re-suspended after freeze-drying for $20 \mathrm{~h}, 24 \mathrm{~h}$ or $30 \mathrm{~h}$ $(n=4$ to 7). (C) Lipoplexes were prepared with siLuc in $\mathrm{NaCl} 150 \mathrm{mM}$, water, or in a solution of glucose or sucrose $(5 \% \mathrm{w} / \mathrm{v})$, before dilution in excipients and freeze-drying $(n=3)$. The results are expressed as $\%$ inhibition of luciferase activity relative to non-transfected cells (means $\pm S D, * p<0.05$ ). siLuc, siRNA specific to luciferase; siCtle, non-inhibitory siRNA. 
Next, Small Angle X-Ray Scattering (SAXS) was used to infer the structure of our particles both in the dry form (freeze-dried powder) and in the liquid form (in suspension). When suspended in $150 \mathrm{mM}$ $\mathrm{NaCl}$ (Figure 3A, green curve), lipoplexes exhibited a mixture of two phases, cubic and lamellar, as we have recently shown. ${ }^{29}$ When the saline suspension of lipoplexes was diluted in the solution of lyophilization excipients (trehalose / mannitol, $2.5 \%$ / $1 \%$ w/v, Figure 3A, blue curve), the cubic phase was no longer detectable and only a lamellar phase with a broad peak was detected. These results point out that the mixture of excipients had a significant influence on the supramolecular structure of the particles (see discussion section).

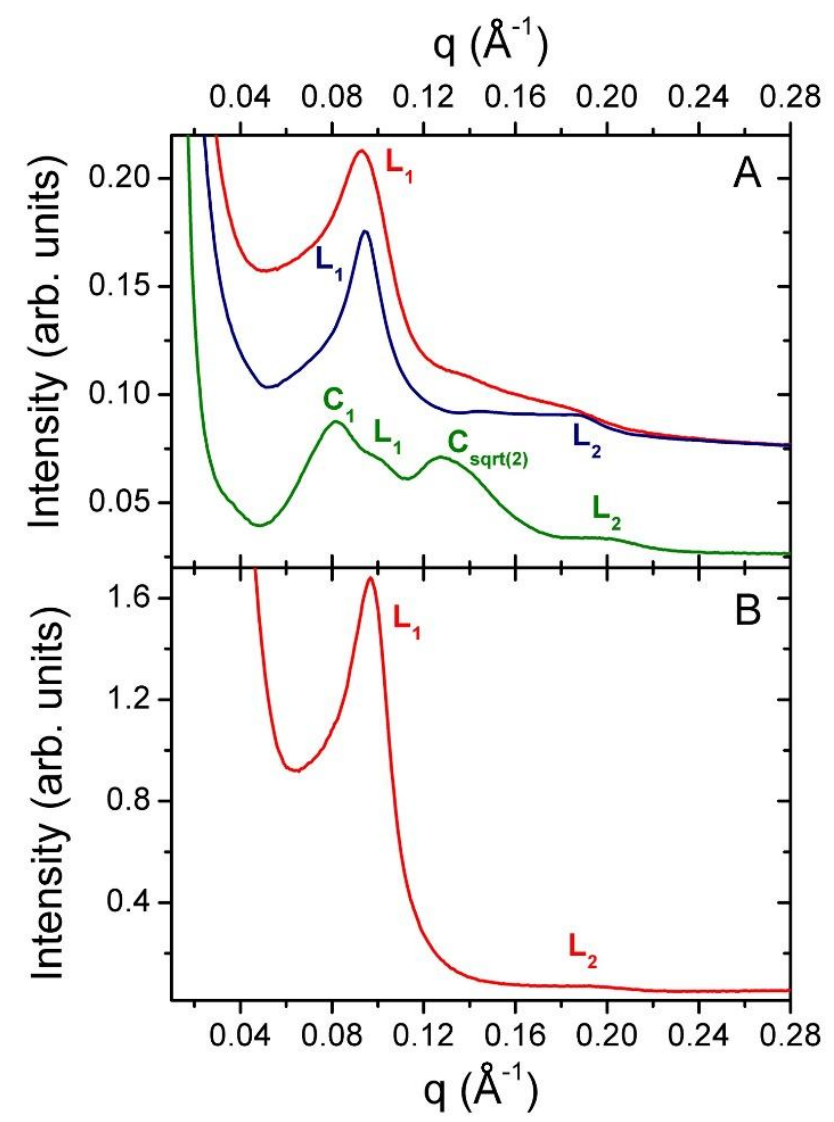

Figure 3. SAXS profiles of lipoplexes in suspension (A) or in freeze-dried form (B). (A) Lipoplexes suspended in $150 \mathrm{mM} \mathrm{NaCl}$ (green curve), in $\mathrm{NaCl}$ supplemented with a solution of trehalose / mannitol ( $2.5 \%$ / 1\% w/v) (blue curve), or re-suspended after freeze-drying (red curve). (B) Freeze-dried lipoplexes.

In the freeze-dried powder containing lipoplexes, a typical lamellar phase signal was found (Figure 3B), and when these freeze-dried lipoplexes were re-suspended, the lamellar phase was preserved (Figure 3A, red curve) exhibiting the same enlargement of the peak observed in the presence of the excipients (Figure 3A, compare blue and red curves). Hence, we have obtained dried siRNA lipoplexes with preserved lamellar structure and gene silencing efficacy. Then, the obtained powder was subsequently used for tableting process. 


\section{Compression of freeze-dried lipoplexes}

Two types of excipient were added to the freeze-dried powder, a spray-dried $\alpha$-lactose monohydrate (FlowLac ${ }^{\circledR} 90$ ) as diluent for direct compression, and magnesium stearate as lubricant. These products were mixed using ceramic grinding beads introduced in the tube. A $160 \mathrm{mg}$ mixture was obtained composed of $76.5 \% \mathrm{w} / \mathrm{w}$ of freeze-dried powder, $23 \% \mathrm{w} / \mathrm{w}$ of diluent and $0.5 \% \mathrm{w} / \mathrm{w}$ of lubricant. This mixture was manually put in the die (diameter of $6 \mathrm{~mm}$ ) of a StyleOne Evolution press. A main compression pressure of $150 \mathrm{MPa}$ was applied to obtain tablets with an average weight of $135 \mathrm{mg}$. It was found that the loss of powder due to mixing process was important. In fact, when ceramic grinding beads were shaken into the tubes, static electricity appeared on the plastic walls. The powder was sticking on tubes and could not been handled. Then, in subsequent experiments, mixture using ceramic beads was replaced by mixture with mortar and pestle to avoid static electricity and decrease loss of powder.
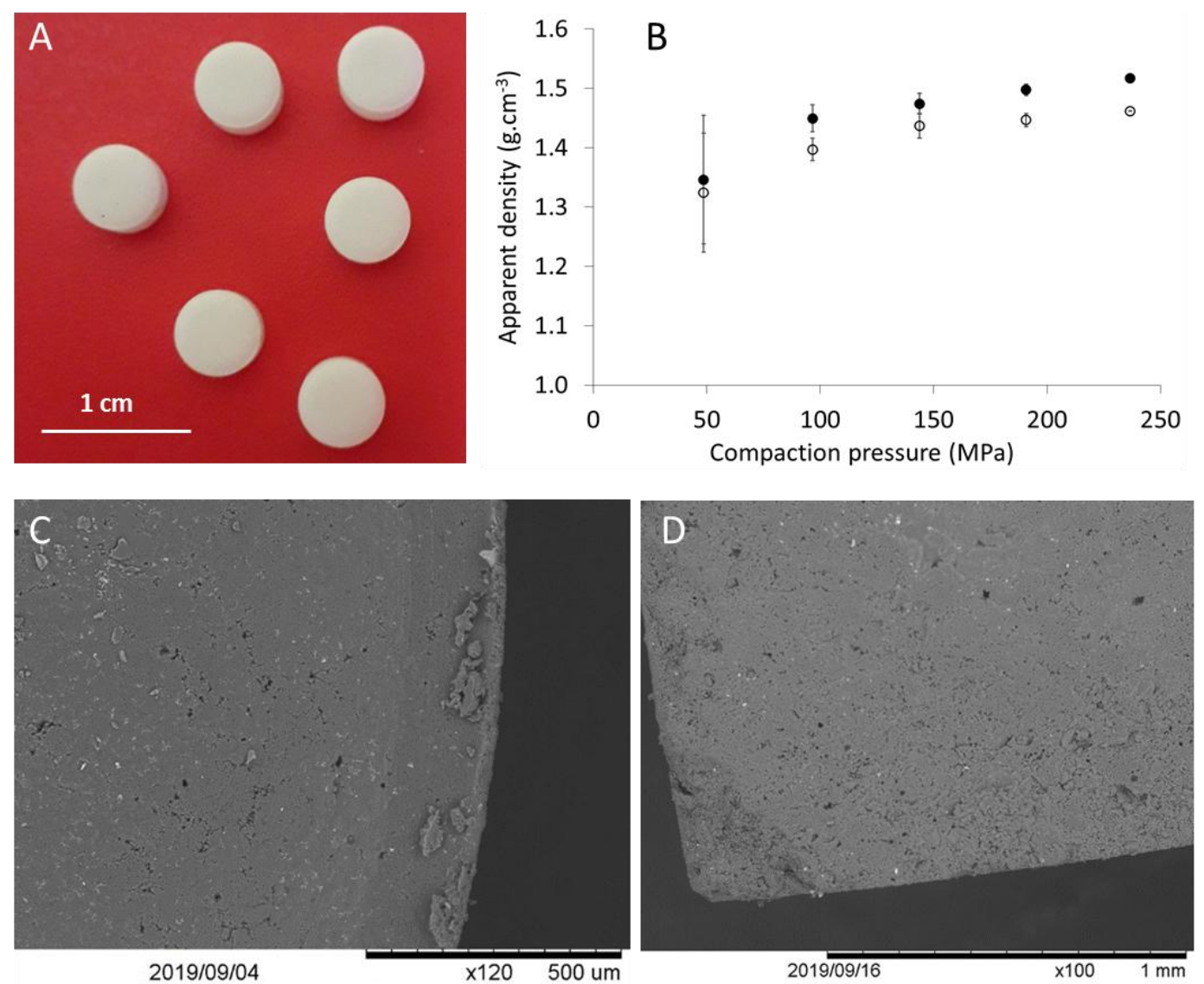

Figure 4. Tablets containing siRNA lipoplexes. (A) Tablets with a diameter of $6 \mathrm{~mm}$ obtained under a compaction pressure of $150 \mathrm{MPa}$. (B) Apparent density measured on tablets with a diameter of $8 \mathrm{~mm}$ (closed symbols: in-die apparent density; opened symbols: out-of-die apparent density). (C, D) SEM pictures of the surface (C) of a tablet $\varnothing=6 \mathrm{~mm}$ ) or the inside (D) a tablet $(\varnothing=8 \mathrm{~mm})$, obtained under $150 \mathrm{MPa}$. Pictures show the low porosity of the tablets. 
In an effort to optimize the compression conditions, tableting of mixtures of lipoplexes-containing freeze-dried powder with diluent and lubricant (mixing process in mortar and pestle) was also performed under main compression pressure from 50 to $250 \mathrm{MPa}$. Tablets with an average weight between 150 and $160 \mathrm{mg}$ were obtained (Figure 4A). The observed variations of the in-die and outof-die apparent densities through the applied pressures were in the range of 1.30 and $1.50 \mathrm{~g} . \mathrm{cm}^{-3}$ for tablets with a diameter of $8 \mathrm{~mm}$ (Figure 4B). The elastic recovery values calculated as previously described ${ }^{19}$ were between $1.7 \%$ and $3.9 \%$ in the range of pressure assayed. Then, the resultant tablets exhibited a low porosity as shown in tablets pictures (Figure 4C-D). Tablets were also submitted to a diametral compression test. ${ }^{30,31}$ However, since they deformed plastically between the two flat platens during the test, it was not possible to measure a breaking force. This particular compaction behavior should be linked to the composition of the mixture, with up to $75 \% \mathrm{w} / \mathrm{w}$ of freeze-dried powder.
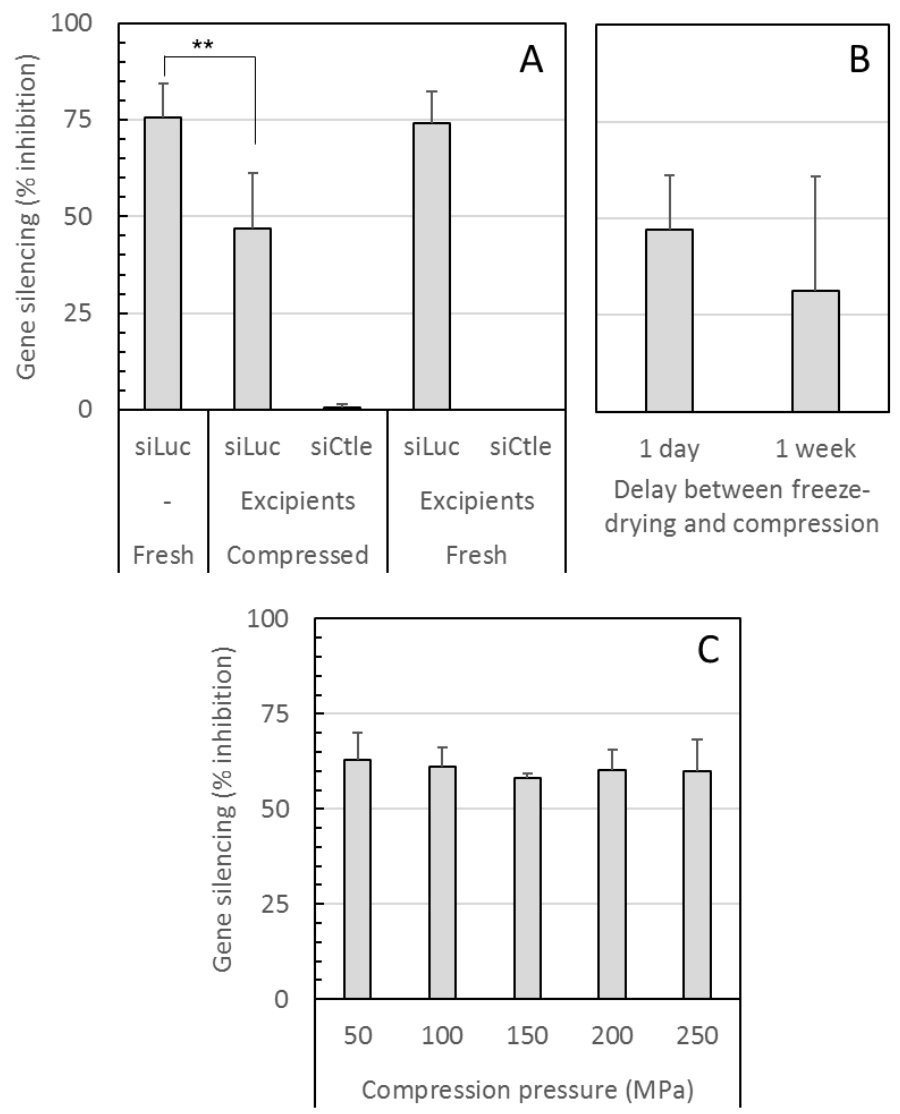

Figure 5. Gene silencing efficacy of lipoplexes re-suspended after compression. (A) Lipoplexes were either freshly prepared (Fresh), or diluted in a solution of freeze-drying (trehalose / mannitol $2.5 \% / 1 \% \mathrm{w} / \mathrm{v}$ ) and tableting (lactose) excipients and tested as such (Excipients fresh), or after freeze-drying, compression ( $\mathrm{P}=150 \mathrm{MPa}$ ) and re-suspension (Excipients compressed) ( $n=3$ to 6). (B) Lipoplexes were prepared with siLuc and re-suspended after freeze-drying and compression with a delay of 1 day or 1 week applied between freeze-drying and compression processes ( $n=3$ to 6). (C) Lipoplexes were prepared with siLuc and re-suspended from tablets obtained with increasing main compression pressures $(n=3)$. The results are expressed as $\%$ inhibition of luciferase activity relative to non-transfected cells (means $\pm S D, * * p<0.01$ ). 
In order to evaluate the gene silencing efficacy of the lipoplexes submitted to compression, the tablets were disintegrated in water and the resulting suspension was assayed on cultured cells and compared with a fresh lipoplexes suspension. As shown in Figure $5 \mathrm{~A}, 62 \%$ of the efficacy of fresh lipoplexes was retained upon compression. We verified that this efficacy was specific as no efficacy was detectable if siRNA luciferase was replaced by siRNA control, and it was not affected by the presence of freeze-drying and tableting excipients, namely trehalose, mannitol and lactose (Figure 5A). We also compared the efficacy of lipoplexes re-suspended from tablets prepared 1 day or 1 week after freeze-drying. As shown in Figure 5B, there was no significant difference between the efficacies obtained but the variability was more pronounced when the freeze-dried solid was kept for several days before submitting it to compression. The efficacy of re-suspended lipoplexes from tablets obtained under increasing compression pressures was compared. It can be seen (Figure 5C) that there was no effect of compression pressure on the efficacy of lipoplexes after re-suspension. This is probably linked with the specific compaction behavior of the freeze-dried samples. As shown in Figure 4B, the changes on the in-die apparent density of tablets was limited above $100 \mathrm{MPa}$. This means that the increase in apparent density, conventionally observed under pressure for pharmaceutical products, would probably be observed at lower values of compaction pressures than those studied here. Then, for future developments, low compaction pressures could be tested in order to observe a possible effect on efficacy.

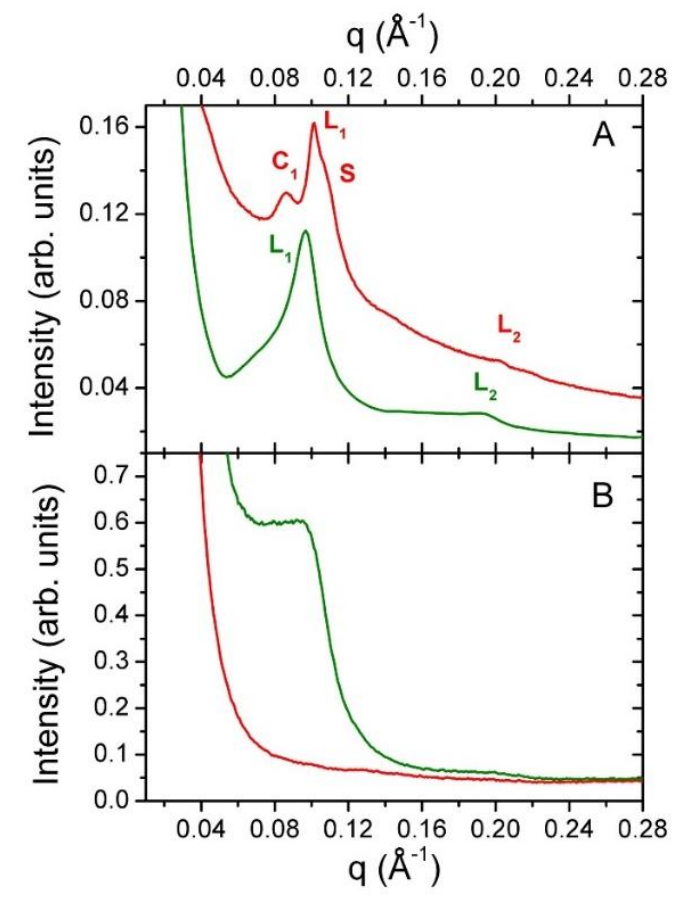

Figure 6. SAXS profiles of lipoplexes in suspension (A) or in crushed tablets (B). (A) Lipoplexes suspended in $150 \mathrm{mM} \mathrm{NaCl}$ supplemented with a solution of trehalose / mannitol / lactose (identical proportions used in freeze-dried samples and tablets) before freeze-drying and compression (green curve), or re-suspended after freeze-drying and compression (red curve). (B) Lipoplexes in crushed tablets (green curve), absence of signal in a placebo (without lipoplexes) tablet prepared under the same conditions but without incorporation of lipoplexes (red curve). 
As for the freeze-drying process, we carried out a SAXS study to determine whether the lipoplexes supramolecular organization was affected by tableting. For this, we used the same strategy and the same method as above, and assayed crushed tablets as well as re-suspended material obtained by disintegration of the tablet in water. As previously observed, when lipoplexes in suspension were mixed with the freeze-drying and compression excipients (trehalose / mannitol / lactose, Figure 6A, green curve), the cubic phase observed in the initial suspension (Figure 3A, green curve) was no longer visible and only a lamellar phase characterized by a broad peak was detectable. When tableting lipoplexes were re-suspended in water (Figure 6A, red curve), contrary to what was observed for the re-suspension of freeze-dried lipoplexes (Figure 3A, red curve) for which only a lamellar phase was detectable, the two phases previously observed, cubic and lamellar were present. Besides the lamellar and cubic phase peaks, an additional signal was also detected (S peak, Figure 6A, red curve), for a value of $q$ around $0.1 \AA^{-1}$. This signal was not previously observed in other sample conditions and may be originated by a short-range ordered phase $S$ (only the fundamental peak is observed, with no high-order signal) of lipoplexes with other packing configuration (e.g. an hexagonal phase). In crushed tablets containing lipoplexes (Figure 6B, green curve), a broad hump centered at $0.1 \AA^{-1}$ was clearly observed. No signal in this q-range was observed in placebo tablets (without lipoplexes) (Figure 6B, red curve). Therefore, this hump can be ascribed to the presence of shortordered lipoplex clusters, which do not pack into the previously discussed cubic and lamellar orders due to the absence of mobility obtained in liquid. One also noticed a slight shift of SAXS peaks on resuspended tableted samples (Figure 6A, red curve) to larger q values with respect to the excipients supplemented (before freeze-drying and compression, Figure 6A, green curve). This indicates a reduction of interplanar distance by a factor of approximately $0.5 \%$ in lamellar and cubic phases.

From the SAXS data of the dried forms (freeze-dried solids and crushed tablets), we also observed in the higher range of q (between 0.5 and $0.8 \AA^{-1}$ ) a series of narrows peaks that could indicate the presence of crystalline forms smaller than the lipid structures, probably related to excipients. These peaks were observed both in placebo or lipoplex-containing samples and disappeared when the powders were suspended upon water addition. In order to identify which compound could trigger the formation of these crystals, freeze-dried solids and crushed tablets of different compositions were analyzed. As shown in Figure 7A, a freeze-dried solid prepared without the addition of mannitol (red curve) exhibited no peaks, contrary to the sample containing mannitol (green curve). In the same way, the removal of mannitol from freeze-drying excipients prevented the appearance of peaks in crushed tablets (red curve, Figure 7B). We then examined the effect of the composition of the freeze-drying excipients on the gene silencing efficacy of the lipoplexes, and in particular the effect of crystallization of mannitol. 

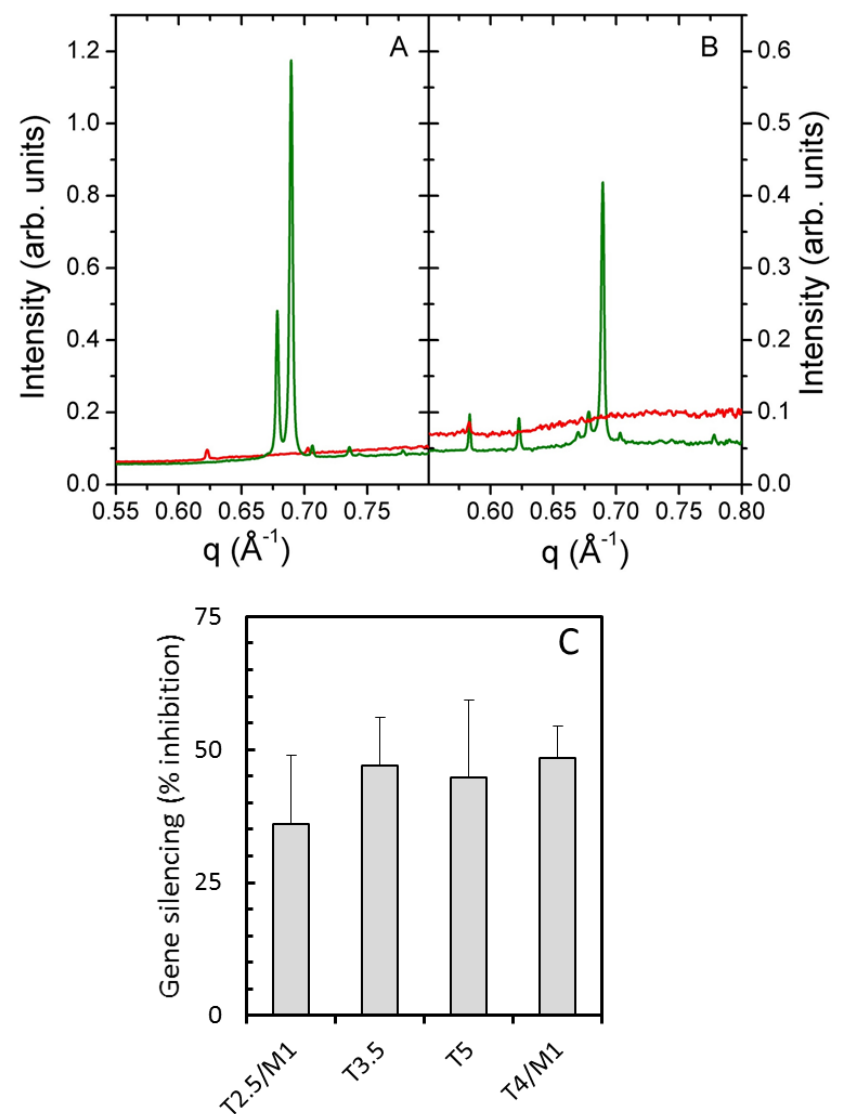

Figure 7. SAXS profiles of freeze-dried powders (A) and crushed tablets (B). (A) Lipoplexes were prepared in $150 \mathrm{mM} \mathrm{NaCl}$ and diluted in a solution of trehalose / mannitol ( $2.5 \% / 1 \%$ ) (green curve) or trehalose (5\%) (red curve) before freezedrying. (B) Compaction was performed on mixtures of lactose, magnesium stearate and freeze-dried lipoplexes containing trehalose / mannitol (2.5\% / 1 \%) (green curve) or trehalose (5\%) (red curve). (C) Efficacy of lipoplexes prepared with siLuc and re-suspended from tablets with different freeze-drying excipient compositions: T2.5/M1: trehalose / mannitol (2.5\% / 1\%), T3.5: trehalose (3.5 \%), T5: trehalose (5\%), T4/M1: trehalose / mannitol (4 \% / $1 \%)(n=3)$. Dilution percentage are for $w / v$.

We therefore prepared freeze-dried solid without adding mannitol, compensating for this absence by increasing the amount of trehalose, compressed them after addition of lactose, and assayed the efficacy of the re-suspended lipoplexes. As shown in Figure 7C, whatever the composition of the excipients, no significant difference could be observed. Finally, we assayed free siRNA in the suspension of lipoplexes after reconstitution (lipoplexes-containing tablet re-suspended in water) using electrophoresis on urea-acrylamide gel as previously described ${ }^{21}$. With this technique, the released siRNAs can be detected when the lipoplexes are loaded onto the gel without any treatment and the intact siRNAs retained inside the particles are detected when lipoplexes are dissociated with Triton treatment before loading onto the gel. As can be seen on the Supplementary Figure S1, the lipoplexes re-suspended from tablets (lane 3) presented no release of free siRNA and kept their siRNA payload intact (lane 8), as did the fresh lipoplexes (lane 1 and lane 6, respectively). The decrease in efficacy observed after compression of the lipoplexes therefore does not seem to result from a leakage of siRNA out of the particles. 


\section{Discussion}

Freeze-drying is extensively used in the pharmaceutical industry to enhance stability and extend shelf-life of many drugs by removing the total water from the drug preparation without exposition to high temperatures. As far as lipid-based formulations like lipoplexes are concerned, the process of freezing and the resultant dehydration can exert stress onto the lipidic structures thus affecting their integrity. ${ }^{10-11}$ The freeze-drying of siRNA lipoplexes has already been studied and the conditions for maintaining their gene silencing efficacy have been reported. ${ }^{32}$ According to the literature, the crucial point for retaining the activity of lipoplexes after re-suspension of the particles is to form a glassy matrix that embed complexes within a highly viscous matrix. The formation of this glassy state depends on freezing temperature and formulation components such as lyoprotectants. Quickfreezing step makes possible to avoid the formation of large ice crystals that may disrupt bilayers and lead to lipoplexes instability. For biopharmaceuticals, sugars and polyols are commonly used as bulking agents and lyoprotectants. The most commonly used are sucrose, trehalose and mannitol. ${ }^{24}$ Based on the literature, we chose to add as lyophilization specific excipients a mixture of mannitol as bulking agent and trehalose as cryo/lyo protectant ${ }^{33}$ and to freeze samples in liquid nitrogen. We showed that upon addition of trehalose and mannitol to lipoplexes in suspension no loss of gene silencing efficacy was observed after re-suspension of freeze-dried lipoplexes.

One of the most commonly occurring supramolecular assemblies which form spontaneously when nucleic acid is complexed with cationic lipid is a multilayer assembly of nucleic acid sandwiched between lamellar bilayer membranes. ${ }^{9}$ Other structures have also been reported, like hexagonal or cubic phases. ${ }^{34}$ Cubic phases are single continuous curved lipid bilayer forming a complex network with 3D cubic symmetry which separates two continuous but non-intersecting water channels. ${ }^{35}$ Their formation is expected when the preferred bilayer curvature is slightly different from that of planar bilayers.

In the case of the lipoplexes used here, they were prepared with equimolar amounts of the cationic lipid DMAPAP and the zwitterionic lipid DOPE (structures in Figure $8 \mathrm{~A}$ ). We have recently shown that the liposome formed with DMAPAP/DOPE and the lipoplexes which result from the mixture of siRNA and DMAPAP/DOPE liposome were in the form of a mixture of two phases, a lamellar phase and a cubic one. ${ }^{29}$ The structure adopted by amphiphilic lipid depends on its morphology and can be inferred from its critical packing parameter or $\mathrm{CPP}^{36}$ (Figure 8B). DOPE, which has a reduced polar head, has a CPP> 1 , which favors the adoption of reverse structure. ${ }^{37}$ DMAPAP, is a lipospermine whose structure is close to that of DOGS or DOSPA with regard to the polar head but with a shorter hydrophobic part, with two $\mathrm{C} 14$ chains rather than two C18 chains (Figure $8 \mathrm{~A}$ ). 
A

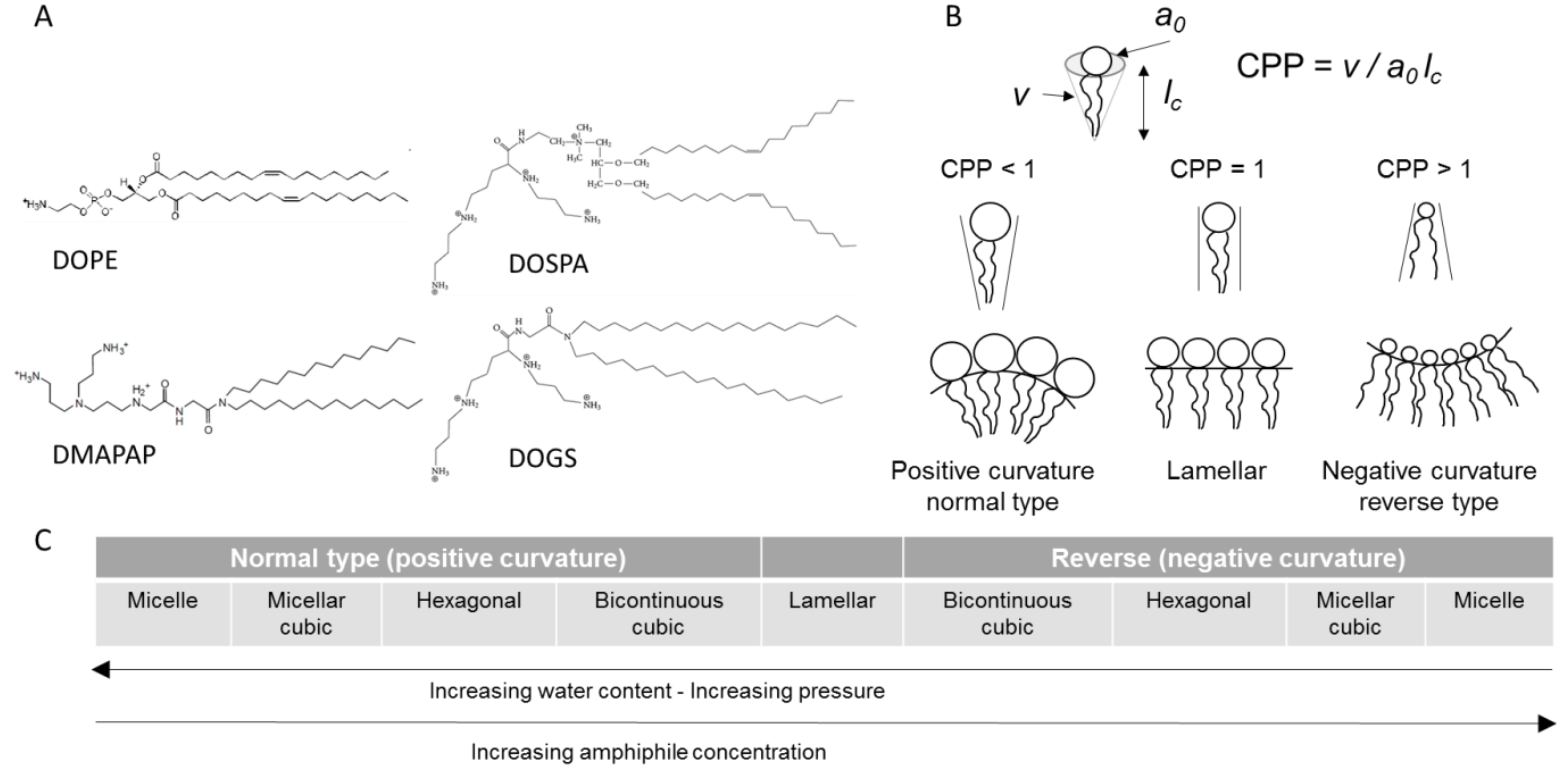

Figure 8. (A) Structure of cationic and zwitterionic lipids. DOPE = 1,2-dioleoyl-sn-glycero-3-phosphoethanolamine, DOSPA = 2,3-dioleyloxy-N-(2(spermine carboxamido) ethyl)-methyl-1-propaniminium, DMAPAP = 2-\{3-[Bis-(3-amino-propyl)-amino]propylamino\}-N-ditetradecylcarbamoyl methyl-acetamide, DOGS = dioctadecylamidoglicyl-spermin. (B) Molecular shapes and critical packing parameter (CPP) of amphiphiles and the structures formed. $v$ = volume of hydrocarbon core, $a_{0}=$ effective head group area, $I_{c}=$ hydrocarbon chain length. $(C)$ Lyotropic liquid crystal phases (an ideal phase progression as a function of amphiphile concentration, pressure or water content in the system, from $^{58}$ ).

DOSPA has a CPP $<1$, associated with a non-inverted micellar structure. ${ }^{37}$ Indeed, for this type of molecule, the size of the polar head prevents the formation of bilayer with a negative curvature. This phenomenon is accentuated by the cationic charges of the polar head which exert a strong repulsion between the adjacent molecules, also preventing the formation of an inverted structure. Pure DOGS was reported to form micelles and only some lamellae were detected when it was mixed with DNA. ${ }^{38}$ For a mixture of lipids with different CPPs, the adopted structure is in an intermediate zone between the forms taken by each pure lipid. So, it has been shown that DOSPA / DOPE liposome adopt lamellar structure but not hexagonal phase. ${ }^{37}$ The presence of the cationic lipid prevents the formation of hexagonal structure, preferred phase by DOPE, and the presence of DOPE allows the mixture to form a planar lamellar phase, that the cationic lipid alone would not be able to adopt easily. Based on these results, it can be deduced that the cubic / lamellar mixture observed for DMAPAP / DOPE, in the form of liposome or lipoplexes, would be a mixture of plane lamellar phase and normal, i.e. not inverse, cubic phase.

We examined the impact of freeze-drying process on the structure of our siRNA delivery vector. We first observed that the dilution of lipoplexes in the solution of sugars led to the disappearance of the cubic phase. It has been shown on other lipids that the addition of sugars, such as sucrose or trehalose, would induce an increase of the CPP. ${ }^{39-40}$ Indeed, these molecules, capable of interacting 
with the polar heads of the lipids induce their dehydration, by replacement of water molecules, which would result in a decrease in the effective volume of the polar head and thus an increase in the $\mathrm{CPP}^{39}$ (Figure $8 \mathrm{C}$ ). In the case of the DMAPAP / DOPE mixture, the effect of sugars, by decreasing the volume of the polar head of the DMAPAP, could favor the plane lamellar structure to the detriment of the normal cubic phase, thus explaining the disappearance of the cubic structure when the excipients (trehalose and mannitol) were added to the lipoplexes suspension (Figure 3). It has been suggested that disaccharides used as excipients during freeze-drying are able to protect the structure of liposomes by substituting for water, thus allowing their native structure to be preserved in a dried state. ${ }^{41}$ Therefore, our SAXS data are consistent with a water replacement event with trehalose, which could explain how the supramolecular structure of lipoplexes was preserved during freeze-drying. Upon re-suspension, lipoplexes retained their structure in lamellar phase, as well as their gene silencing efficacy.

While lipoplexes did not lose their efficacy during freeze-drying, it appeared that after compression, more than $60 \%$ of the gene silencing efficacy was retained. Since freeze-drying powder retained complete activity compared to compressed tablets, another formulation strategy based on lyophilized orally disintegrating tablets could also be considered. This strategy has the advantage of not requiring steps for handling powder. However, freeze-dried tablets have characteristics of freezedried solids and their high porosity results in a lower mechanical strength and a higher hygroscopicity compared to tablets obtained by compaction, which compromises their handling and especially their stability. Optimization of the packaging is therefore necessary to protect the tablets from moisture and mechanical stress during transport and handling. Both formulation strategies, freeze-dried or compressed tablets, have advantages and disadvantages and both deserve to be explored. Our choice fell on compression because unlike lyophilized orally disintegrating tablets which release the drug on the tongue, a compressed tablet makes it possible to release its content further down the digestive tract.

However, we have tried to understand the reasons for this loss of efficacy. We first made the hypothesis that this decrease in gene silencing activity could be due to complete or partial crystallization of bulking agents, but we showed that it was not the case since the removal of mannitol among the excipients, which induced the disappearance of the detectable crystals in SAXS, did not induce an increase in the efficacy of lipoplexes after compression and re-suspension (Figure 7C). The effect of compression on the siRNA molecule had also to be considered. Oligonucleotide tablets have already been described for preclinical ${ }^{42}$ and clinical application. ${ }^{43-44}$ Although no details on the tableting conditions were given, it appears that the activity of the oligonucleotide was not impacted by the tableting process. It was in this case a 2'O-methyl-phosphorothioate-modified 
single-stranded RNA oligonucleotide, simply integrated into a tablet, without a delivery system. In our case, the oligonucleotide is double-stranded and its duplex structure is necessary for its activity. It has been shown that the helical forms of DNA and RNA are little affected by pressure because their structure depends mostly on hydrogen bonds ${ }^{45}$, and that water plays an important role in the pressure-induced denaturation of nucleic acid, like in pressure denaturation of proteins where the driving force of the denaturation process is the penetration of water into the protein core and the release of solvent-excluded cavities. ${ }^{46}$ However, these data were reported for molecules in solution, submitted to high pressure. Since we applied compression forces to a dry form, a denaturing effect of siRNA due to the presence of water could be excluded. An interesting point to study and additional experiments should be performed to conclude on the effect of residual water on the retained efficacy of the compressed lipoplexes in future work. For example, it is possible to reduce the secondary drying to obtain powders with higher residual water. During compaction, we can also apply an extended dwell-time (up to $100000 \mathrm{~ms}$ ) to increase the time under pressure of the freezedried solid.

During compression, lipids adapt to volume restriction by changing their conformation and packing. Since a delicate balance of competing energetic contributions is involved in stabilization of lipid phases, such small changes in conformation determine large structural transformations. ${ }^{47}$ In the case of lipids, increasing pressure results in a reduction in hydrocarbon chain motion and a corresponding increase in chain ordering which will tend to reduce the cross sectional area of the lipid hydrocarbon tail region. Since the head group cross section is influenced far less by pressure, increasing pressure will tend to increase the spontaneous curvature toward the chain region. ${ }^{48}$ Thus, various pressureinduced phase transitions have been observed in a DOPE/water system, in particular a transition from the inverse hexagonal $\left(H_{\|}\right)$to the lamellar $L \alpha$ phase. ${ }^{49}$ For a direct phase forming system, namely DTAC (dodecyl-trimethyl-ammonium chloride)/water, increasing pressure on very dry samples induced the transitorily formation of a lamellar $L \alpha$ phase at the cubic - hexagonal phase transition. ${ }^{50}$ These studies have, however, been performed on lipid suspensions of varying hydration degree but not on completely dried or freeze-dried forms. Some molecular dynamics simulations of the structural change in lipid bilayers ${ }^{51}$ or lipid vesicle ${ }^{52}$ generated by shock waves have also been reported. Bilayers permeabilization events, lateral displacement and tilts of lipid molecules have been shown. All these data show that bilayer lipid structures may be sensitive to compressive forces or a shock wave, which could explain the partial loss of lipoplexes efficacy that we observed upon tableting. Compression may induce heat shock in the tablet. However, the increase of temperature seems to be relatively modest. Klinzing et al. ${ }^{53}$ have measured a surface temperature of $31.5^{\circ} \mathrm{C}$ on a post-ejection tablet composed of unlubricated microcrystalline cellulose and used numerical 
simulation to predict internal temperatures and obtained a maximum of $38^{\circ} \mathrm{C}$. In this work, powders were lubricated to limit frictions and compaction was performed at the minimal speed of the press. In addition, nucleic acid molecules are known to be particularly heat resistant.

Freeze-drying did not alter the structure of the lipoplexes since a typical lamellar phase signal was observed both in the freeze-dried solid and in the re-suspended material. In contrast, compression seemed to have more effect on the structure. The signal observed on the crushed tablet was too broad to characterize a phase but it appeared at a q value close to that of the lamellar phase observed in suspension or in the freeze-dried solid. After disintegration of the tablet, the resuspended lipoplexes no longer presented a single lamellar structure but a mixture of phases, probably lamellar and cubic. It can be hypothesized that compression may have had a deleterious effect on the bilayer structure of the lipoplexes, which explains why only part of their gene silencing efficacy was retained. Since it has long been known ${ }^{13,54-55}$ that the efficacy of lipoplexes strongly depends on the structure adopted by the lipids used in the formulation, a modification of this structure can reasonably explain a loss of efficacy. In order to increase the resistance of the lipid structures to compression, it is possible to envisage modifying the lipid composition of the lipoplexes in order to introduce lipids allowing them to better maintain this structure. Further optimization of the compression conditions will be necessary to maintain the structure and activity of lipoplexes.

Although there are some reports of compressing biomolecules into tablets, like antisense oligonucleotides ${ }^{43-44}$, proteins ${ }^{56}$, or even particles, like silica-lipid-mannitol microparticles ${ }^{57}$, we are the first to show that it is possible to submit a cationic lipid-based siRNA delivery system to compressive forces while maintaining some of its gene silencing efficacy. The ability to formulate siRNA vectors in tablet opens the way for oral administration of siRNA-based drugs.

\section{Acknowledgment}

Financial support was provided by CAPES, COFECUB, CNRS, INSERM and Paris Descartes University. We acknowledge SOLEIL for provision of synchrotron radiation facilities and we would like to thank Javier PEREZ and Youssef LIATIMI for assistance in using beamline SWING. We are also grateful to ESRF (Grenoble, France) and the members of beamline ID02, especially Theyencheri NARAYANAN, for giving us access to the beamline, which allowed us to carry out the preliminary experiments necessary to develop the following tests. We are grateful to Dr. Marie CARRIERE for her help in performing SAXS experiments at ESRF. We also acknowledge IQ Mobil Solutions GmBH for providing the Tempris wireless temperature system during this work.

\section{Supporting information}

Supplementary Figure S1: Gel retardation assay of siRNA lipoplexes. 


\section{References}

(1) Zhong, H.; Chan, G.; Hu, Y.; Hu, H.; Ouyang, D. A Comprehensive Map of FDA-Approved Pharmaceutical Products. Pharmaceutics 2018, 10, 263.

(2) Busignies, V.; Charrueau, C., Tchoreloff, P.; Escriou, V. Nanostructures for oral delivery of therapeutic nucleic acids. in Nanostructures for Oral Medicine, Andronescu, E., Grumezescu, A.M., Eds.; Elsevier: Cambridge, 2017; pp 147-169.

(3) Weng, Y.; Xiao, H.; Zhang, J.; Liang, X.-J.; Huang, Y. RNAi therapeutic and its innovative biotechnological evolution. Biotechnol. Adv. 2019, 37(5), 801-825.

(4) Haussecker, D. Current issues of RNAi therapeutics delivery and development. J. Control. Release 2014, 195, 49-54.

(5) Buck, J.; Grossen, P.; Cullis, P.R.; Huwyler, J.; Witzigmann, D. Lipid-Based DNA Therapeutics: Hallmarks of Non-Viral Gene Delivery. ACS Nano 2019, 13, 3754-3782.

(6) Adams, D.; Gonzalez-Duarte, A.; O'Riordan, W.D.; Yang, C.C.; Ueda, M.; Kristen, A.V.; Tournev, I.; Schmidt, H.H.; Coelho, T.; Berk, J.L.; Lin, K.P.; Vita, G.; Attarian, S.; Planté-Bordeneuve, V.; Mezei, M.M.; Campistol, J.M.; Buades, J.; Brannagan 3rd, T.H.; Kim, B.J.; Oh, J.; Parman, Y.; Sekijima, Y.; Hawkins, P.N.; Solomon, S.D.; Polydefkis, M.; Dyck, P.J.; Gandhi, P.J.; Goyal, S.; Chen, J.; Strahs, A.L.; Nochur, S.V.; Sweetser, M.T.; Garg, P.P.; Vaishnaw, A.K.; Gollob, J.A.; Suhr, O.B. Patisiran, an RNAi Therapeutic, for Hereditary Transthyretin Amyloidosis. New Engl. J. Med. 2018, 379(1), 11-21.

(7) Foldvari, M.; Chen, D.W.; Nafissi, N.; Calderon, D.; Narsineni, L.; Rafiee, A. Non-viral gene therapy: Gains and challenges of non-invasive administration methods. J. Control. Release 2016, 240, 165-190.

(8) O’Driscoll, C.M.; Bernkop-Schnürch, A.; Friedl, J.D.; Préat, V.; Jannin, V. Oral delivery of non-viral nucleic acid-based therapeutics - do we have the guts for this? Eur. J. Pharm. Sci. 2019, 133, 190-204.

(9) Dan, N.; Danino, D. Structure and kinetics of lipid-nucleic acid complexes. Adv. Colloid. Interface Sci. 2014, 205, 230-239.

(10) Ball, R.L.; Bajaj, P.; Whitehead, K.A. Achieving long-term stability of lipid nanoparticles: examining the effect of pH, temperature, and lyophilization. Int. J. Nanomed. 2017, 12, 305-315.

(11) Wilkhu, J.S.; McNeil, S.E.; Anderson, D.E.; Kirchmeier, M.; Perrie, Y. Development of a solid dosage platform for the oral delivery of bilayer vesicles. Eur. J. Pharm. Sci. 2017, 108, 71-77.

(12) Abdelwahed, W.; Degobert, G.; Stainmesse, S.; Fessi, H. Freeze-drying of nanoparticles: Formulation, process and storage considerations. Adv. Drug Deliv. Rev. 2006, 58, 1688-1713.

(13) Tenchov, B.G.; Wang, L.; Koynova, R.; MacDonald, R.C. Modulation of a membrane lipid lamellar-nonlamellar phase transition by cationic lipids: A measure for transfection efficiency. Biochim. Biophys. Acta 2008, 1778, 2405-2412. 
(14) Ngo, D.; Beaulieu, E.; Gu, R.; Leaney, A.; Santos, L.; Fan, H.; Yang, Y.; Kao, W.; Xu, J.; Escriou, V.; Loiler, S.; Vervoordeldonk, M.J.; Morand, E.F. Divergent Effects of Endogenous and Exogenous Glucocorticoid-Induced Leucine Zipper in Animal Models of Inflammation and Arthritis. Arthritis Rheum. 2013, 65(5), 1203-1212.

(15) Présumey, J.; Courties, G.; Louis-Plence, P.; Escriou, V.; Scherman, D.; Pers, Y.-M.; Yssel, H.; Pène, J.; Kyburz, D.; Gay, S.; Jorgensen, C.; Apparailly, F. Nicotinamide phosphoribosyltransferase / visfatin expression by inflammatory monocytes mediates arthritis pathogenesis. Ann. Rheum. Dis. 2013, 72(10), 1717-1724.

(16) Bedarida, T.; Domingues, A.; Baron, S.; Ferreira, C.; Vibert, F.; Cottart, C.-H.; Paul, J.-L.; Escriou, V.; Bigey, P.; Gaussem, P.; Leguillier, T.; Nivet-Antoine, V. Reduced endothelial thioredoxininteracting protein protects arteries from damage induced by metabolic stress in vivo. FASEB J. 2018, 32, 3108-3118.

(17) Byk, G.; Scherman, D.; Schwartz, B.; Dubertret, C. Lipopolyamines as Transfection Agents and Pharmaceutical Uses Thereof, US Patent 6171612, 2001.

(18) Schlegel, A.; Bigey, P.; Dhotel, H.; Scherman, D.; Escriou, V. Reduced in vitro and in vivo toxicity of siRNA-lipoplexes with addition of polyglutamate. J. Control. Release 2013, 165, 1-8.

(19) Mazel, V.; Busignies, V.; Diarra, H.; Tchoreloff, P. On the links between elastic constants and effective elastic behavior of pharmaceutical compacts: importance of Poisson's ratio and use of bulk modulus. J. Pharm. Sci. 2013, 102(11), 4009-4014.

(20) Rhinn, H.; Largeau, C.; Bigey, P.; Lai Kuen, R.; Richard, M.; Scherman, D.; Escriou, V. How to make siRNA lipoplexes efficient? Add a DNA cargo. Biochim. Biophys. Acta 2009, 1790, 219-230.

(21) Hamoudi, M.C.; Henry, E.; Zerrouk, N.; Scherman, D.; Arnaud, P.; Deprez, E.; Escriou, V. Enhancement of siRNA lipid-based vector stability and siRNA integrity in human serum with addition of anionic polymer adjuvant. J. Drug Deliv. Sci. Technol. 2015, 26, 1-9.

(22) Schlegel, A.; Largeau, C.; Bigey, P.; Bessodes, M.; Lebozec, K.; Scherman, D.; Escriou, V. Anionic polymers for decreased toxicity and enhanced in vivo delivery of siRNA complexed with cationic liposomes. J. Control. Release 2011, 152, 393-401.

(23) Escriou, V.; Bigey, P.; Scherman, D. Vectors including an anionic macromolecule and a cationic lipid for delivering small nucleic acids, European Patent EP2389158, 2009.

(24) Jorgensen, L.; Hostrup, S.; Moeller, E.H.; Grohganz, H. Recent trends in stabilizing peptides and proteins in pharmaceutical formulation - considerations in the choice of excipients. Expert Opin. Drug Deliv. 2009, 6(11), 1219-30.

(25) Parkins, D.A.; Lashmar, U.T. The formulation of biopharmaceutical products. Pharm. Sci. Technol. Today 2000, 3(4), 129-137. 
(26) Loisel, S.; Floch, V.; Le Gall, C.; Férec, C. Factors influencing the efficiency of lipoplexes mediated gene transfer in lung after intravenous administration. J. Liposome Res. 2001, 11, 127-138.

(27) Smisterova, J.; Wagenaar, A.; Stuart, M.C.A.; Polushkin, E.; ten Brinke, G.; Hulst, R.; Engberts, J.B.F.N.; Hoekstra, D. Molecular Shape of the Cationic Lipid Controls the Structure of Cationic Lipid/Dioleylphosphatidylethanolamine-DNA Complexes and the Efficiency of Gene Delivery. J. Biol. Chem. 2001, 276, 47615-47622.

(28) Hattori, Y.; Yoshizawa, T.; Koga, K.; Maitani, Y. NaCl Induced High Cationic Hydroxyethylated Cholesterol-Based Nanoparticle-Mediated Synthetic Small Interfering RNA Transfer into Prostate Carcinoma PC-3 Cells. Biol. Pharm. Bull. 2008, 31, 2294-2301.

(29) Arruda, D.C.; Gonzalez, I.J.; Finet, S.; Cordova, L.; Trichet, V.; Andrade, G.F.; Hoffmann, C.; Bigey, P.; de Almeida Macedo, W.A.; Da Silva Cunha Jr, A.; Malachias de Souza, A.; Escriou, V. Modifying internal organization and surface morphology of siRNA lipoplexes by sodium alginate addition for efficient siRNA delivery. J. Colloid. Interface Sci. 2019, 540, 342-353.

(30) EUP, 2016. 2.9.8 resistance to crushing of tablets, European Pharmacopeia. Eur. Directorate Qual. Med. Healthcare 299.

(31) USP, 2013. <1217> Tablet Breaking Force, The United States Pharmacopeia-National Formulary, USP35 NF30. U.S. Pharmacopeia.

(32) Yadava, P.; Gibbs, M.; Castro, C.; Hughes, J.A. Effect of Lyophilization and Freeze-thawing on the Stability of siRNA-liposome Complexes. AAPS PharmSciTech 2008, 9(2), 335-341.

(33) Allison, S.D.; Anchordoquy, T.J. Mechanisms of Protection of Cationic Lipid-DNA Complexes during Lyophilization. J. Pharm. Sci. 2000, 89, 682-691.

(34) Dittrich, M.; Brauer, C.; Funari, S.S.; Dobner, B.; Brezesinski, G.; Wölk, C. Interactions of Cationic Lipids with DNA: A Structural Approach. Langmuir 2018, 34, 14858-14868.

(35) Tenchov, B.; Koynova, R. Cubic phases in membrane lipids. Eur. Biophys. J. 2012, 41, 841-850.

(36) Kulkarni, C.V. Lipid crystallization: from self-assembly to hierarchical and biological ordering. Nanoscale 2012, 4, 5779-5791.

(37) Simberg, D.; Danino, D.; Talmon, Y.; Minsky, A.; Ferrari, M.E.; Wheeler, C.J.; Barenholz, Y. Phase, behavior, DNA ordering, and Size Instability of Cationic Lipoplexes. Relevance to optimal transfection activity. J. Biol. Chem. 2001, 276(50), 47453-47459.

(38) Boukhnikachvili, T.; Aguerre-Chariol, O.; Airiau, M.; Lesieur, S.; Ollivon, M.; Vacus, J. Structure of in-serum transfecting DNA-cationic lipid complexes. FEBS Letters 1997, 409, 188-194.

(39) Koynova, R.; Brankov, J.; Tenchov, B. Modulation of lipid phase behavior by kosmotropic and chaotropic solutes. Experiment and thermodynamic theory. Eur. Biophys. J. 1997, 25, 261-274.

(40) Wang, Z.; Zheng, L.; Inoue, T. Effect of sucrose on the structure of a cubic phase formed from a monoolein/water mixture. J. Colloid. Interface Sci. 2005, 288, 638-641. 
(41) Crowe, L.M.; Womersley, C.; Crowe, J.H.; Reid, D.; Appel, L.; Rudolph, A. Prevention of fusion and leakage in freeze-dried liposomes by carbohydrates. Biochim. Biophys. Acta 1986, 861, 131-140.

(42) Raoof, A.A.; Chiu, P.; Ramtoola, Z.; Cumming, I.K.; Teng, C.; Weinbach, S.P.; Hardee, G.E.; Levin, A.A.; Geary, R.S. Oral Bioavailability and Multiple Dose Tolerability of an Antisense Oligonucleotide Tablet Formulated with Sodium Caprate. J. Pharm. Sci. 2004, 93(6), 1431-1439.

(43) Tillman, L.G.; Geary, R.S.; Hardee, G.E. Oral Delivery of Antisense Oligonucleotides in Man. J. Pharm. Sci. 2008, 97, 225-236.

(44) Monteleone, G.; Neurath, M.F.; Ardizzone, S.; Di Sabatino, A.; Fantini, M.C.; Castiglione, F.; Scribano, M.L.; Armuzzi, A.; Caprioli, F.; Sturniolo, G.C.; Rogai, F.; Vecchi, M.; Atreya, R.; Bossa, F.; Onali, S.; Fichera, M.; Corazza, G.R.; Biancone, L.; Savarino, V.; Pica, R.; Orlando, A.; Pallone, F. Mongersen, an Oral SMAD7 Antisense Oligonucleotide, and Crohn's Disease. New Engl. J. Med. 2015, 372(12), 1104-1113.

(45) Silva, J.L.; Oliveira, A.C.; Vieira, T.C.R.G.; de Oliveira, G.A.P.; Suarez, M.C.; Foguel, D. HighPressure Chemical Biology and Biotechnology. Chem. Rev. 2014, 114, 7239-7267.

(46) Rayan, G.; Macgregor Jr, R.B. Pressure-induced helix-coil transition of DNA copolymers is linked to water activity. Biophys. Chem. 2009, 144, 62-66.

(47) Winter, R.; Dzwolak, W. Exploring the temperature-pressure configurational landscape of biomolecules: from lipid membranes to proteins. Phil. Trans. $R$ Soc. A 2005, 363, 537-563.

(48) Brooks, N.J.; Ces, O.; Templer, R.H.; Seddon, J.M. Pressure effects on lipid membrane structure and dynamics. Chem. Phys. Lipids 2011, 164(2), 89-98.

(49) Pisani, M.; Narayanan, T.; Di Gregorio, G.M., Ferrero, C.; Finet, S.; Mariani, P. Compressing inverse lyotropic systems: Structural behavior and energetics of dioleoyl phosphatidyl ethanolamine. Phys. Rev. 2003, 68(2 Pt1), 021924.

(50) Paccamiccio, L.; Pisani, M.; Spinozzi, F.; Ferrero, C.; Finet, S.; Mariani, P. Pressure Effects on Lipidic Direct Phases: The Dodecyl Trimethyl Ammonium Chloride-Water System. J. Phys. Chem. B 2006, 110, 12410-12418.

(51) Koshiyama, K.; Kodama, T.; Yano, T.; Fujikawa, S. Molecular dynamics simulation of structural changes of lipid bilayers induced by shock waves: Effects of incident angles. Biochim. Biophys. 2008, $1778,1423-1428$.

(52) Sliozberg, Y.; Chantawansri, T. Damage in spherical cellular membrane generated by the shock waves: Coarse-grained molecular dynamics simulation of lipid vesicle. J. Chem. Phys. 2014, 141, 184904.

(53) Klinzing, G.R.; Zavaliangos, A.; Cunningham, J.; Mascaro, T.; Winstead, D. Temperature and density evolution during compaction of capsule shaped tablet. Comput. Chem. Eng. 2010, 34, 10821091. 
(54) Ewert, K.K.; Ahmad, A.; Evans, H.M.; Safinya, C.R. Cationic lipid-DNA complexes for non-viral gene therapy: relating supramolecular structures to cellular pathways. Expert Opin. Biol. Ther. 2005, 5, 33-53.

(55) Safinya, C.R. Structures of lipid-DNA complexes: supramolecular assembly and gene delivery. Curr. Opin. Struct. Biol. 2001, 11, 440-448.

(56) Wei, Y.; Wang, C.; Jiang, B.; Sun, C.C.; Middaugh, C.R. Developing Biologics Tablets: The Effects of Compression on the Structure and Stability of Bovine Serum Albumin and Lysozyme. Mol. Pharm. 2019, 16, 1119-1131.

(57) Bremmell, K.E.; Tan, A.; Martin, A.; Prestidge, C.A. Tableting Lipid-based Formulations for Oral Drug Delivery: A Case Study with Silica Nanoparticle-Lipid-Mannitol Hybrid Microparticles. J. Pharm. Sci. 2013, 102(2), 684-693.

(58) Kaasgaard, T.; Drummond, C.J. Ordered 2-D and 3-D nanostructured amphiphile self-assembly materials stable in excess solvent. Phys. Chem. Chem. Phys. 2006, 8, 4957-4975.

\section{For Table of Contents Use Only}

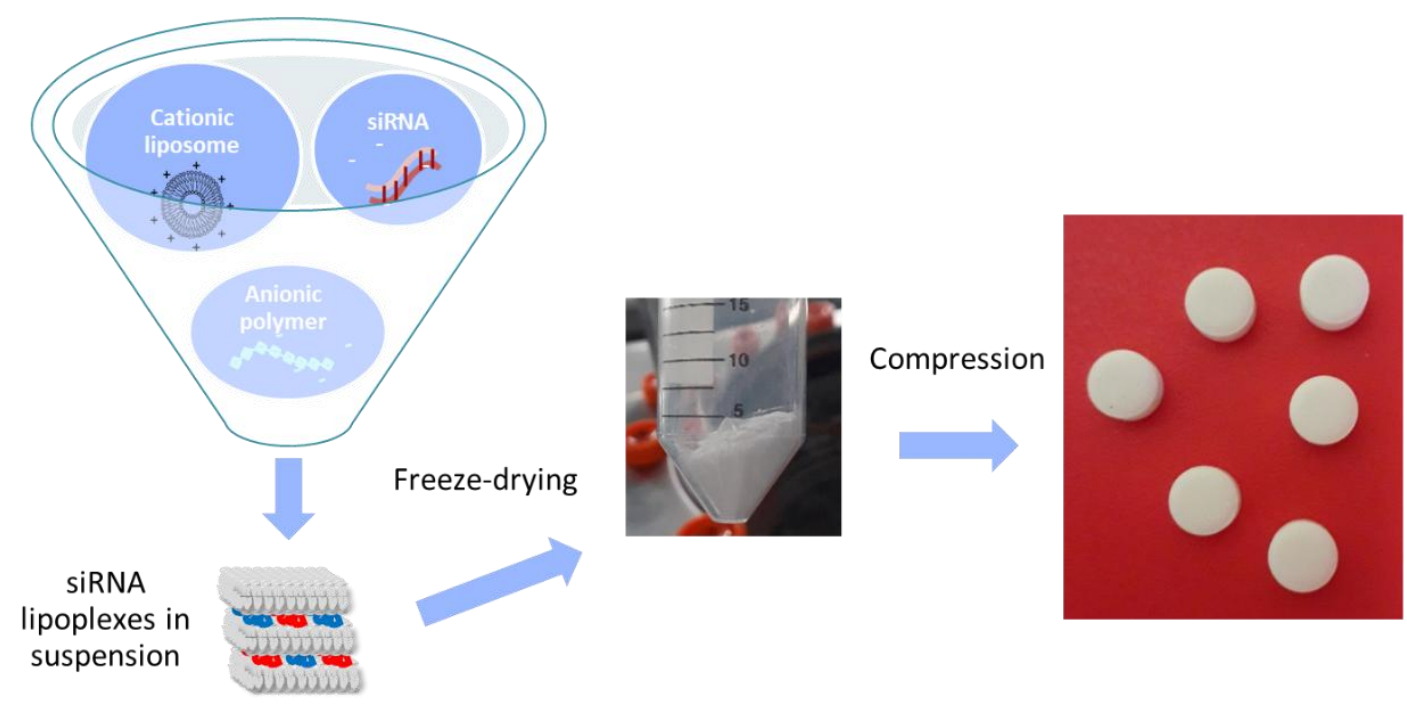

Compression of vectors for small interfering RNAs delivery: toward oral administration of siRNA lipoplexes in tablet form By V Busignies, DC Arruda, C Charrueau, MCS Ribeiro, A-M Lachagès, A Malachias, S Finet, AU Rehman, P Bigey, P Tchoreloff, V Escriou 